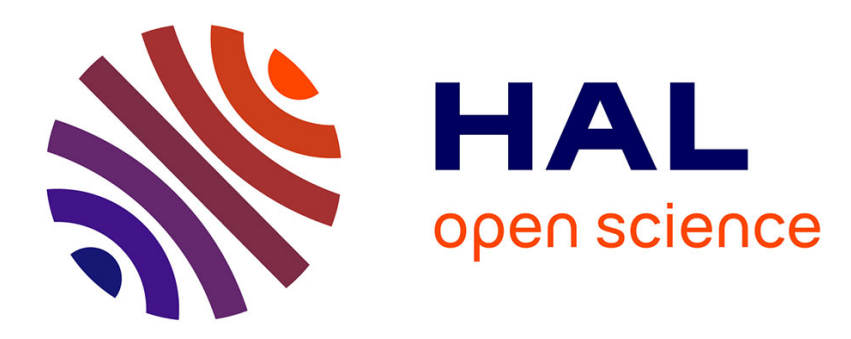

\title{
EXAFS Study of Ball-Milled Elemental Nanocrystalline Powders
}

\author{
P. Schilling, J.-H. He, E. Ma
}

\section{To cite this version:}

P. Schilling, J.-H. He, E. Ma. EXAFS Study of Ball-Milled Elemental Nanocrystalline Powders. Journal de Physique IV Proceedings, 1997, 7 (C2), pp.C2-1221-C2-1222. 10.1051/jp4:19972203 . jpa-00255275

\section{HAL Id: jpa-00255275 https://hal.science/jpa-00255275}

Submitted on 1 Jan 1997

HAL is a multi-disciplinary open access archive for the deposit and dissemination of scientific research documents, whether they are published or not. The documents may come from teaching and research institutions in France or abroad, or from public or private research centers.
L'archive ouverte pluridisciplinaire HAL, est destinée au dépôt et à la diffusion de documents scientifiques de niveau recherche, publiés ou non, émanant des établissements d'enseignement et de recherche français ou étrangers, des laboratoires publics ou privés. 


\title{
EXAFS Study of Ball-Milled Elemental Nanocrystalline Powders
}

\author{
P.J. Schilling, J.-H. He* and E. Ma* \\ Center for Advanced Microstructures and Devices (CAMD), Louisiana State University, Baton Rouge, LA \\ 70803, U.S.A. \\ * Department of Mechanical Engineering, Louisiana State University, Baton Rouge, LA 70803, U.S.A.
}

\begin{abstract}
Nanocrystalline elemental powders of $\mathrm{Cr}, \mathrm{Fe}, \mathrm{Ni}$, and $\mathrm{Cu}$ were prepared by high-energy ball milling and studied using EXAFS spectroscopy. Data were acquired in total electron yield to avoid thickness effects, and a detailed analysis was performed to obtain structural parameters. While significant amplitude reduction was observed in the EXAFS signals of the ball-milled powders, reduction in first neighbor coordination number based on curve-fitting was limited to $\leq 15 \%$. The results are consistent with the presence of nanocrystalline structures and structural defects induced by the milling process.
\end{abstract}

\section{INTRODUCTION}

In this study we present results of EXAFS analysis of nanocrystalline elemental powders $(\mathrm{Cr}, \mathrm{Fe}, \mathrm{Ni}, \mathrm{Cu})$ prepared by highenergy ball milling. EXAFS provides an excellent tool for studying nanocrystalline materials, but has also engendered some controversy, particularly concerning reduction of the first neighbor coordination number and the structure of grain boundaries as described in [1] and references therein. The problem becomes more complicated when dealing with nanocrystalline powders prepared by high-energy ball milling because, in addition to characteristics intrinsic to the nanophase materials, the drastic mechanical process may induce other changes in the structure. An extensive study found a dramatic decrease in the firstneighbor coordination number in ball-milled nanocrystalline Fe as a function of milling time [2]. Recently reported results from ball-milled $\mathrm{Fe}-\mathrm{Cu}$ alloys [3], which included EXAFS of a pure Fe powder, also suggested significant amplitude reduction. However, the previous studies $[2,3]$ were performed in transmission, and suffer from potential experimental artifacts (thickness effects) $[1,4,5]$. Here we report results from EXAFS data collected in total electron yield (TEY) from nanocrystalline iron powders prepared by high-energy ball milling, along with similarly prepared elemental powders of $\mathrm{Cr}, \mathrm{Ni}$, and $\mathrm{Cu}$.

\section{EXPERIMENTAL PROCEDURE}

Elemental powders of $\mathrm{Cr}(99.95 \%$ pure, 200 mesh), $\mathrm{Fe}(99 \%, 450$ mesh), Ni $(99.9 \%$ pure, 3-7 $\mu \mathrm{m})$, and $\mathrm{Cu}(99 \%$ pure, 450 mesh) were milled in a Spex 8000 laboratory mill in argon atmosphere using hardened steel balls and vial with a ball to powder weight ratio (b:p) of 5:1. The $\mathrm{Cu}$ and $\mathrm{Ni}$ powders were milled at liquid nitrogen temperature to avoid excessive cold welding. Ball-milled $\mathrm{Cr}, \mathrm{Fe}$, and $\mathrm{Ni}$ powders sieved with a 450 mesh to obtain fine powders, along with as-milled $\mathrm{Cu}$ (milling of the $\mathrm{Cu}$ produced a flaky material which could not be sieved), were pressed to Kapton tape to prepare samples for EXAFS. Samples of as-received coarse-grained powders prepared in this manner gave EXAFS signals almost identical to polycrystalline foil standards. EXAFS experiments were performed at the $K$ edges of $\mathrm{Cr}(5989 \mathrm{eV}), \mathrm{Fe}(7112 \mathrm{eV}), \mathrm{Ni}(8333 \mathrm{eV})$, and $\mathrm{Cu}(8979$ $\mathrm{eV}$ ) using the LNLS double crystal monochromator [6], operating with $\mathrm{Si}(220)$ crystals, at the CAMD light source (1.5 $\mathrm{GeV}$, $150 \mathrm{~mA}$ maximum current). Data were acquired using a total electron yield detector [7]. Data analysis was performed using the UWXAFS software package [8] with phase and amplitude functions obtained from FEFF [9]. In addition to the samples prepared for this study, an Fe sample (ball milled $16 \mathrm{hr}$. with b:p $=4: 1$ ) previously studied in transmission [3] was analyzed using TEY data.

\section{RESULTS AND DISCUSSION}

Fourier transforms of EXAFS signals from representative ball-milled nanocrystalline powders are compared to signals from the corresponding coarse-grained metals in Figure 1. Fitting results for the first peaks in the Fourier transforms appear in Table I. (Fitting of the first peaks in the transforms of the bcc $\mathrm{Cr}$ and $\mathrm{Fe}$ samples involved two coordination spheres, with the results for the first sphere appearing in Table I.) A reduction in amplitude is observed in the EXAFS signals of the ball-milled powders. Through the fitting analysis, this amplitude reduction is partly attributed to a decrease in the first shell coordination number, giving $\mathrm{N} / \mathrm{N}_{0}=0.85$ for ball-milled $\mathrm{Ni}\left(8 \mathrm{hr}\right.$.) and $\mathrm{N} / \mathrm{N}_{0} \geq 0.9$ for all other samples. Along with the decrease in coordination number, fitting results exhibit an increase in the Debye-Waller term and larger uncertainties in these correlated parameters. 


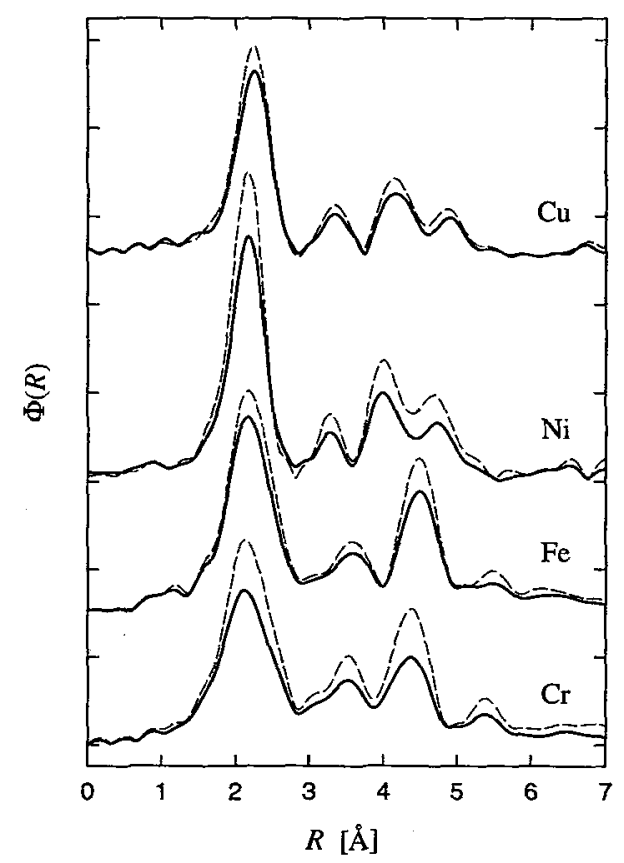

Figure 1. Fourier Transforms $\Phi(R)$ of $k \chi(k)$ for ball-milled nanocrystalline powders (solid lines) of $\mathrm{Cr}, \mathrm{Fe}, \mathrm{Ni}$, and $\mathrm{Cu}$, and the corresponding polycrystalline powder standards (dashed lines).
Table I. Results of fits to ball-milled (BM) nanocrystalline metal samples. The scaling factors $\left(s_{0}^{2}\right)$ were set to give the correct coordination numbers $(\mathrm{N})$ in the coarse-grained metal. $\sigma_{1}^{2}$ is the mean square deviation (at room temperature) about the average bond distance $r$ of the first coordination shell. All BM powders were prepared with a ball to powder weight ratio (b:p) of 5:1 except where noted. The uncertainties reported here are the results of curve fitting and reflect only the random fluctuation component of the measurement uncertainty.

\begin{tabular}{|c|c|c|c|}
\hline Sample & $\mathrm{N}$ & $r(\AA)$ & $\sigma_{1}^{2}\left(\AA^{2}\right)$ \\
\hline $\mathrm{Cu}^{*}$ & 12 & $2.548 \pm 0.003$ & $0.0082 \pm 0.0004$ \\
\hline $\mathrm{BM} 8 \mathrm{hr}^{*}$ & $11.1 \pm 0.8$ & $2.551 \pm 0.005$ & $0.0087 \pm 0.0007$ \\
\hline $\mathrm{Ni}^{*}$ & 12 & $2.486 \pm 0.002$ & $0.0052 \pm 0.0003$ \\
\hline BM $8 \mathrm{hr}^{*}$ & $10.2 \pm 0.9$ & $2.493 \pm 0.006$ & $0.0058 \pm 0.0008$ \\
\hline $\mathrm{Fe}^{*}$ & 8 & $2.481 \pm 0.003$ & $0.0040 \pm 0.0003$ \\
\hline BM $8 \mathrm{hr}$ & $7.7 \pm 0.4$ & $2.480 \pm 0.003$ & $0.0044 \pm 0.0003$ \\
\hline BM $16 \mathrm{hr}^{*}$ & $7.4 \pm 0.4$ & $2.480 \pm 0.004$ & $0.0043 \pm 0.0004$ \\
\hline BM $16 \mathrm{hr}^{*}$ & $7.6 \pm 0.4$ & $2.482 \pm 0.004$ & $0.0045 \pm 0.0003$ \\
\hline $\mathrm{Cr}^{*}$ & 8 & $2.510 \pm 0.006$ & $0.0040 \pm 0.0007$ \\
\hline $\mathrm{BM} 8 \mathrm{hr}$ & $7.9 \pm 0.6$ & $2.510 \pm 0.007$ & $0.0050 \pm 0.0008$ \\
\hline BM $16 \mathrm{hr}^{*}$ & $7.2 \pm 0.7$ & $2.505 \pm 0.010$ & $0.0054 \pm 0.0012$ \\
\hline
\end{tabular}

"FT shown in Figure 1.

${ }^{+} \mathrm{b}: \mathrm{p}=4: 1$

When uncertainties are considered, the coordination numbers are in most cases near the nominal values. The $16 \mathrm{hr}$., $4: 1 \mathrm{~b}: \mathrm{p}$ Fe sample $\left(\mathrm{N} / \mathrm{N}_{0}=0.95\right)$ was previously analyzed using transmission data [3] which showed greater amplitude reduction (fitting results indicated $\mathrm{N} / \mathrm{N}_{0} \sim 0.7$ ), presumably due to particle size effects [5]. No dramatic reductions in coordination number like those reported by Di Cicco et al. $\left(\mathrm{N} / \mathrm{N}_{0}=0.5\right)$ [2] were observed here. In the ball-milled Ni sample, which displayed the largest reduction in coordination number, slight changes were observed in the near edge structure, suggesting possible contamination incurred during the milling process. Although TEY is surface sensitive ( $100 \mathrm{~nm}$ depth), no deviation was observed in the transforms which would indicate significant presence of oxides. Thus, as in [1], oxide contamination is estimated to be less than $15 \%$, the sensitivity of EXAFS measurements. If the conclusion of Stern et al. [1] that the grain boundaries in the nanophase are not anomalous is employed, coordination number reduction due to the increased grain boundary content of the nanocrystalline material should be limited to a few percent for the grain size typically seen in ball-milled metals (10 - $20 \mathrm{~nm}$ ) [10]. Decreases in coordination number beyond this must be attributed to effects of ball milling. This could be mainly due to the presence of structural defects [2] induced by the high energy mechanical process. Such an explanation suggests that structural defects other than grain boundaries (vacancies, dislocations, impurities. etc.) are responsible for decreases in coordination number of up to $\sim 15 \%$. This magnitude seems to be more reasonable than that previously reported for ball-milled $\mathrm{Fe}[2]$.

\section{References}

[1] Stern E.A., Siegel R.W., Newville M., Sanders P.G., and Haskel D., Phys. Rev. Lett. 75 (1995) 3874-3877.

[2] Di Cicco A., Berrettoni M. Stizza S., Bonetti E., and Cocco G., Phys. Rev. B 50 (1994) 12386-12397.

[3] Schilling P.J., He J.-H., Cheng J., and Ma E., Appl. Phys. Lett. 68 (1996) 767-769.

[4] Stern E.A. and Kim K., Physical Review B 23 (1981)3781-3787.

[5] Lu K.-Q. and Stem E.A., Nucl. Instrum. Methods 12 (1983) 475-478.

[6] Corrêa M.C.,Tolentino H.,Craievich A., and Cusatis C., Rev. Sci. Instrum. 63 (1992) 896-898.

[7] Lytle F.W., Greegor R.B., Via G.H., Brown J.M., and Meitzner G., J. de Physique 47 (1986) C8 149-151.

[8] Newville M., Ravel B., Haskel D., Rehr J.J., Stern E.A., and Yakoby Y., Physica B 208\&209 (1995) 154-156.

[9] Rehr J.J., Zabinsky S.I. and Albers R.C., Phys. Rev. Lett. 69 (1992) 3397-3400.

[10] Eckert J., Holzer J.C., Krill C.E., and Johnson W.L., J. Mater. Res. 7 (1992) 1751-1761. 